\title{
Bony Metastases of Anaplastic Oligodendroglioma Respond to Temozolomide
}

\author{
Tara Morrison, Juan M. Bilbao, Guisheng Yang, James R. Perry
}

\begin{abstract}
Background: Fewer than 30 cases of oligodendroglioma or anaplastic oligodendroglioma metastatic to bone are reported in the literature. Prolonged survival even with therapy is uncommon. Methods: We report a case of anaplastic oligodendroglioma metastatic to bone with a dramatic and durable response to temozolomide therapy. A retrospective case review, molecular analysis, and literature search were performed. Results: The patient presented with a right frontal mass in 1990. Progression led to resection of the lesion in 1995. Histology revealed an anaplastic oligodendroglioma and the tumour was found to have allelic loss of heterozygosity (LOH) of chromosome 1p (1p-). He received standard radiation therapy. In 2000 he developed hip and pelvic pain. A bone scan showed multiple skeletal lesions. Magnetic resonance imaging of the brain showed stability of intracranial disease. Resection of one lesion found metastatic anaplastic oligodendroglioma with identical morphology to the patient's original tumour, including glial fibrillary acidic protein expression. The patient was started on standard temozolomide chemotherapy and celecoxib with prompt pain relief, and rapid normalization of serum alkaline phosphatase. He received a total of 12 cycles of combined therapy with no toxicity and no evidence of progression until increasing pain marked disease recurrence. The patient underwent palliative chemo- and radiation therapy but eventually succumbed. Discussion: Loss of heterozygosity 1p- is associated with prolonged survival in anaplastic oligodendroglioma and may increase the cumulative risk for development of systemic metastases. We speculate that metastases from oligodendroglioma harbouring loss of heterozygosity at chromosome 1p- retain the chemosensitivity of the initial lesion.
\end{abstract}

RÉSUMÉ: Métastases osseuses d'un oligodendrogliome anaplasique répondant au témozolomide. Introduction: Moins de 30 cas d'oligodendrogliomes ou d'oligodendrogliomes anaplasiques avec métastases osseuses ont été rapportés dans la littérature. Une survie prolongée, même avec le traitement, est rare. Méthodes: Nous rapportons un cas d'oligodendrogliome anaplasique avec métastases osseuses qui a répondu de façon dramatique et durable au traitement par le témozolomide. Une revue rétrospective de cas, une analyse moléculaire et une revue de littérature ont été effectuées. Résultats: À la consultation initiale en 1990, le patient était porteur d'une masse frontale droite. La progression de la lésion a nécessité une résection de la lésion en 1995. L'anatomopathologie a montré qu'il s'agissait d'un oligodendrogliome anaplasique avec perte d'hétérozygotie allélique au niveau du chromosome 1p. Le patient a reçu de la radiothérapie standard. En 2000, il a présenté des douleurs à la hanche et au bassin. Une scintigraphie osseuse a montré des lésions squelettiques multiples. L'imagerie par résonance magnétique du cerveau a montré que la pathologie intracrânienne était stable. La résection d'une des lésions a montré qu'il s'agissait d'une métastase d'un oligodendrogliome anaplasique, dont la morphologie était identique à celle de la tumeur originale du patient, incluant l'expression de la protéine gliale fibrillaire acide. Le patient a reçu une chimiothérapie standard au moyen du témozolomide et de célécoxib qui a entraîné rapidement un soulagement de la douleur et une normalisation de la phosphatase alcaline. Il a reçu un total de 12 cycles de thérapie combinée sans toxicité et sans signe de progression. Par la suite, une recrudescence de la douleur a révélé la présence d'une récidive. Le patient a subi une chimiothérapie et une radiothérapie palliatives et il a éventuellement succombé à la maladie. Discussion: La perte d'hétérozygotie 1p- est associée à une survie prolongée dans l'oligodendrogliome anaplasique et peut augmenter le risque cumulatif de développer des métastases systémiques. Nous discutons de la possibilité que les métastases des oligodendrogliomes qui comportent une perte d'hétérozygotie du chromosome $1 \mathrm{p}$ conservent la chimiosensibilité de la lésion initiale.

Can. J. Neurol. Sci. 2004; 31: 102-108

Primary cerebral tumours rarely metastasize outside the central nervous system, with medulloblastoma and some meningiomas providing occasional exceptions. Local recurrence and extension of gliomas is not uncommon while ventricular and subarachnoid dissemination is recognized but unusual. Remote metastases of gliomas, however, remain an unusual
From the Division of Neurology, Crolla Family Brain Tumour Research Unit (TM, JRP); Division of Neuropathology (JMB, GY); Sunnybrook and Women's College Health Sciences Centre, University of Toronto, Toronto, Ontario, Canada Received June 4, 2003. Accepted in final form August 14, 2003. Reprint requests to: James Perry, Division of Neurology, Sunnybrook and Women's College Health Sciences Centre, Room A4-02, 2075 Bayview Avenue, Toronto, Ontario, Canada M4N 3M5 


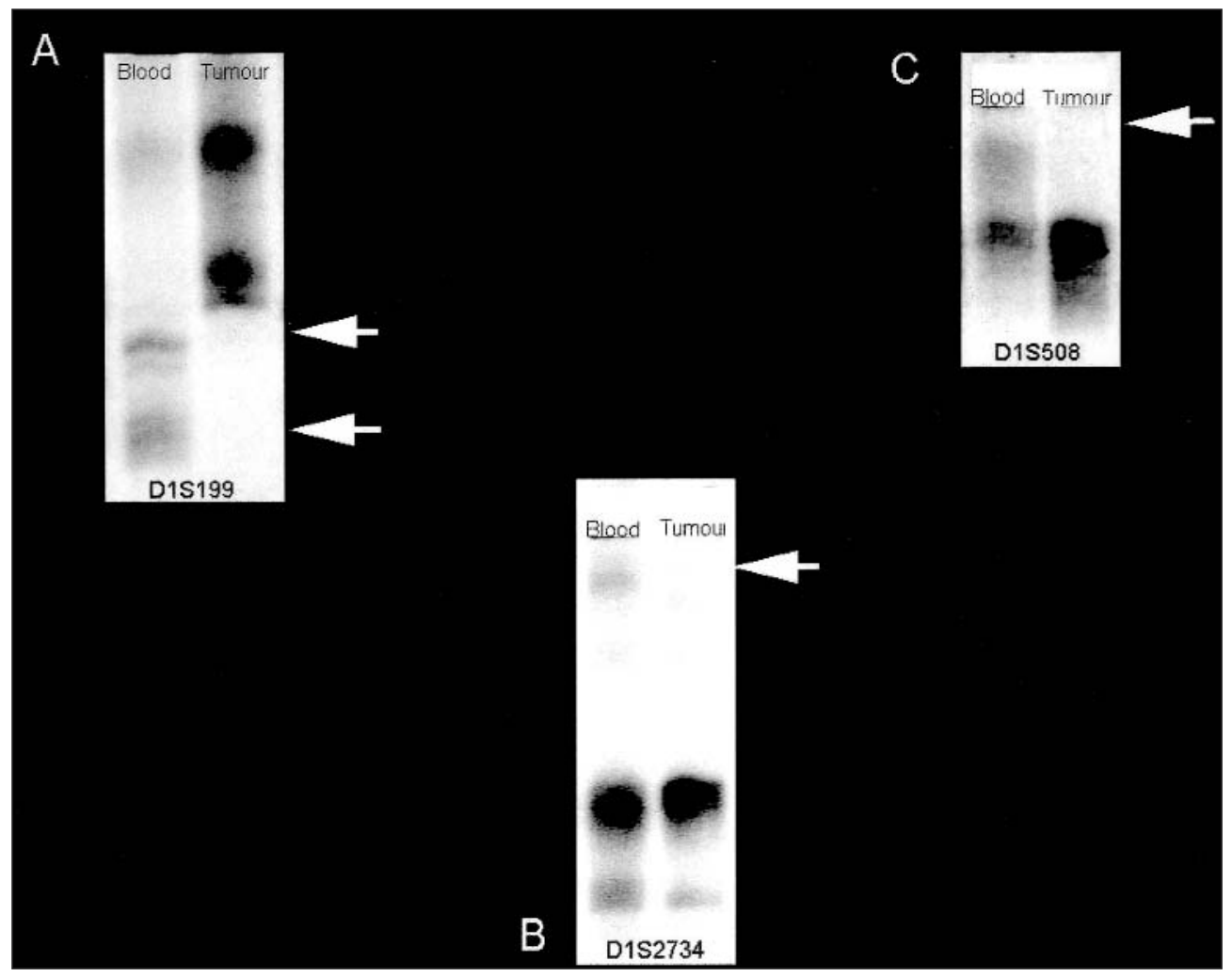

Figure 1: Loss of heterozygosity assay. A: For marker D1S199; B: for marker D1S2734 and C: for marker D1S508. The left lane of each panel (blood) represents constitutional DNA, the right lane (tumour) represents tumour DNA.

manifestation of this tumour. We present here an interesting and unusual case of an anaplastic oligodendroglioma that systemically metastasized several years after successful local therapy.

\section{CaSe Report}

The patient was a 35-year-old male when he had his first seizure in 1977. At that time, a work-up was done, including a CT scan of the head, which was negative. He was well until 1990 , when he had a second seizure. Magnetic resonance imaging (MRI) then revealed a nonenhancing mass in the right frontal lobe that was presumed to be a lowgrade glioma and was observed for several years without change. In 1995, the lesion developed new regions of contrast-enhancement and, on resection, pathology revealed it to be an anaplastic oligodendroglioma that would later be shown to have allelic loss of heterozygosity ( $\mathrm{LOH})$ at chromosome 1p (LOH 1p-) (Figure 1, A-C). He received standard external beam radiation therapy to the brain (5000 cGy).

In 2000, he began to experience significant hip and pelvic pain that limited his activities. A bone scan and CT pelvis revealed multiple skeletal lesions that were felt to be consistent with metastatic cancer (Figure $2 \mathrm{~A}$ ). Repeat MRI of the brain demonstrated complete stability of his cerebral tumour (Figure 2 B). Since the patient's father had died of prostate cancer, and the patient had a marginally elevated PSA $(3.73 \mu \mathrm{g} / \mathrm{L}$ with upper limit of normal at $3.50 \mu \mathrm{g} / \mathrm{L})$, metastatic prostate cancer was suspected. After two failed attempts at CT-guided aspiration of a sacral lesion, the patient underwent open wedge resection of an iliac lesion. It was found, to the surprise of all involved, to be metastatic anaplastic oligodendroglioma, identical in morphology to his previous cerebral tumour, including immunohistochemical expression of glial fibrillary acidic protein (Figure 3, A-C). Hormonal therapy, started for the presumptive diagnosis of metastatic prostate cancer was stopped, and the patient was sent to neuro-oncology. Temozolomide was started at $150 \mathrm{mg} / \mathrm{m}^{2} / \mathrm{d}$ for five days out of 28 along with celecoxib $400 \mathrm{mg}$ twice daily, beginning in October 2000. The patient experienced significant pain relief within one month of initiating therapy. A total of 12 cycles were given in all, with no significant hematologic toxicity. The patient's bony disease stabilized on nuclear bone scans for over 12 months.

Table 1: Primers used for LOH 1p analysis of blood and tumour DNA (results of analysis shown in Figure 1).

\begin{tabular}{|c|c|c|}
\hline D1S199(A) & 20 mer & 5' GGT GAC AGA GTG AGA CCC TG 3', \\
\hline D1S199(B) & 20 mer & 5' CAA AGA CCA TGT GCT CCG TA 3' \\
\hline D1S508(A) & 24 mer & 5' AGC TGG GGA ATA TAT GTN TCA TAT 3' \\
\hline D1S508(B) & 16 mer & 5' TGT GGA AGG CCA ACT C 3', \\
\hline D1S2734(A) & 19 mer & 5' GGT TCA AGG GAT TCT CCT G 3' \\
\hline D1S2734(B) & 17 mer & 5' TGG CAC TCA GAC CTC AA 3' \\
\hline
\end{tabular}




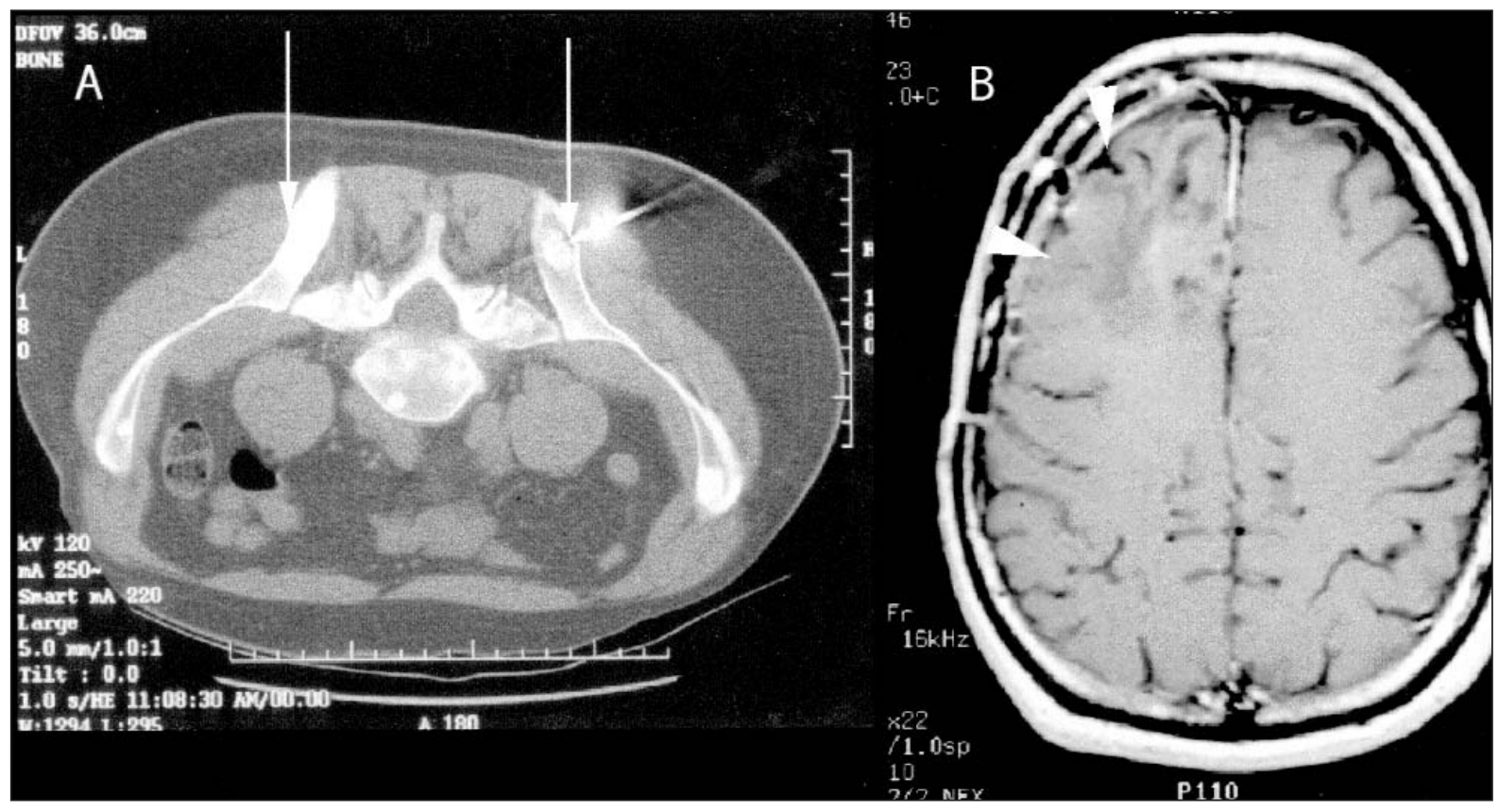

Figure 2: A. CT pelvis with intravenous contrast demonstrating multiple areas of hyperintensity representing increased uptake of contrast in areas of metastatic tumour to the wings of the ilia, posterior iliac spines (arrows), and vertebral body. The metallic object with artifact represents the needle insertion for CT-guided biopsy.

B. MRI head with intravenous gadolinium contrast injection from 1999 demonstrating large right frontal mass with little to no enhancement, some encephalomalacia.

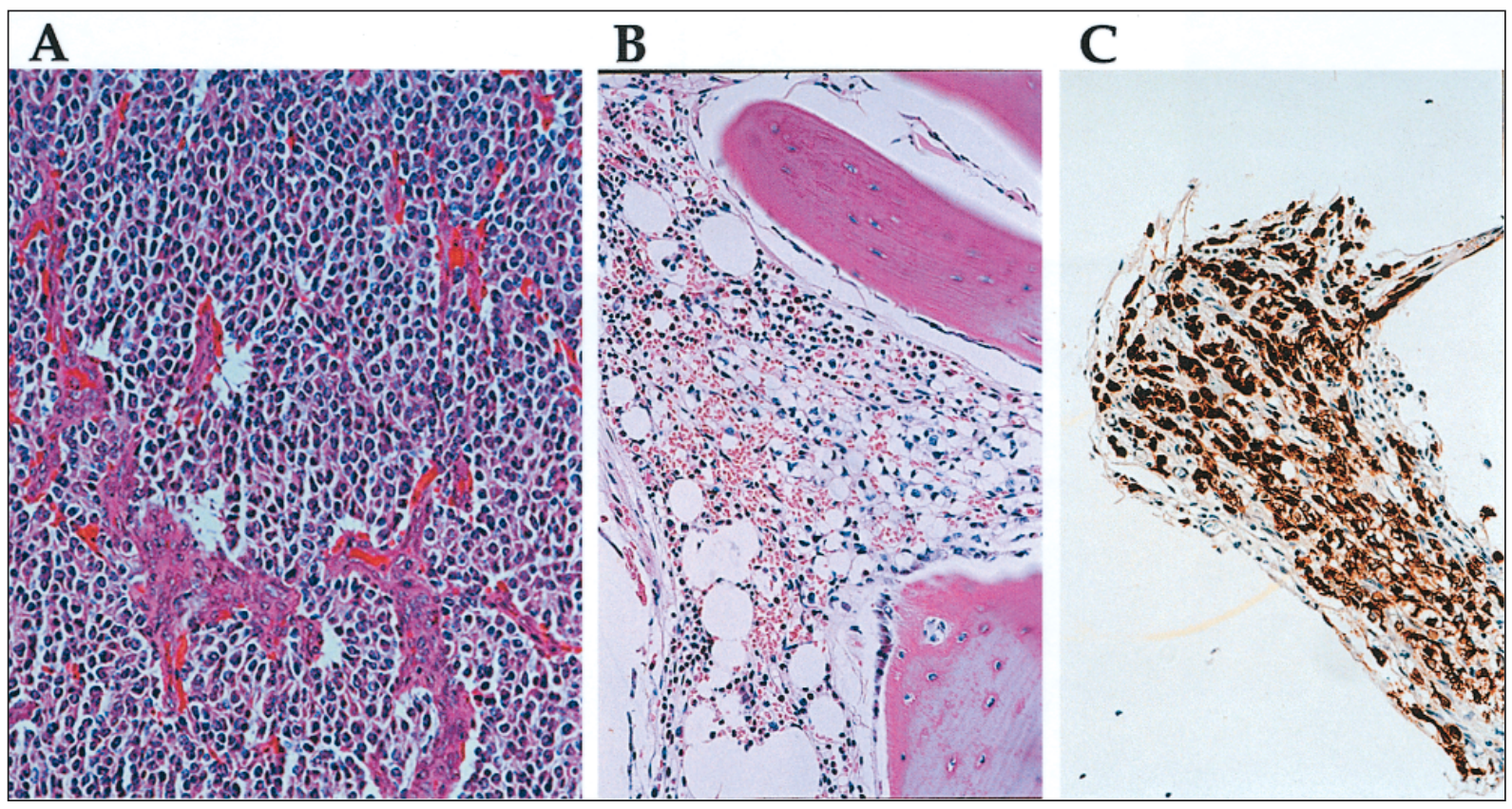

Figure 3: A. Original brain tumour resection specimen revealing densely packed cells with round to oval nuclei and peri-nuclear clearing or typical "fried-egg" appearance of oligodendroglial cells. Some fine capillaries seen in the background as well as endothelial vascular proliferation (hematoxylin and eosin, medium power).

$\boldsymbol{B}$. Bone from iliac crest lesion biopsy demonstrating infiltration of bone marrow spaces with neoplastic cells. These cells have large perinuclear halos (hematoxylin and eosin, medium power).

C. High-power photomicrograph of glial fibrillary acidic protein immunostain of bone lesion showing intense staining of neoplastic cells for this marker of nervous system cells. The patient's original tumour was glial fibrillary acidic protein positive. 
Table 2: Clinical Features of Patients with Extracranial Metastases of Oligodendroglioma*

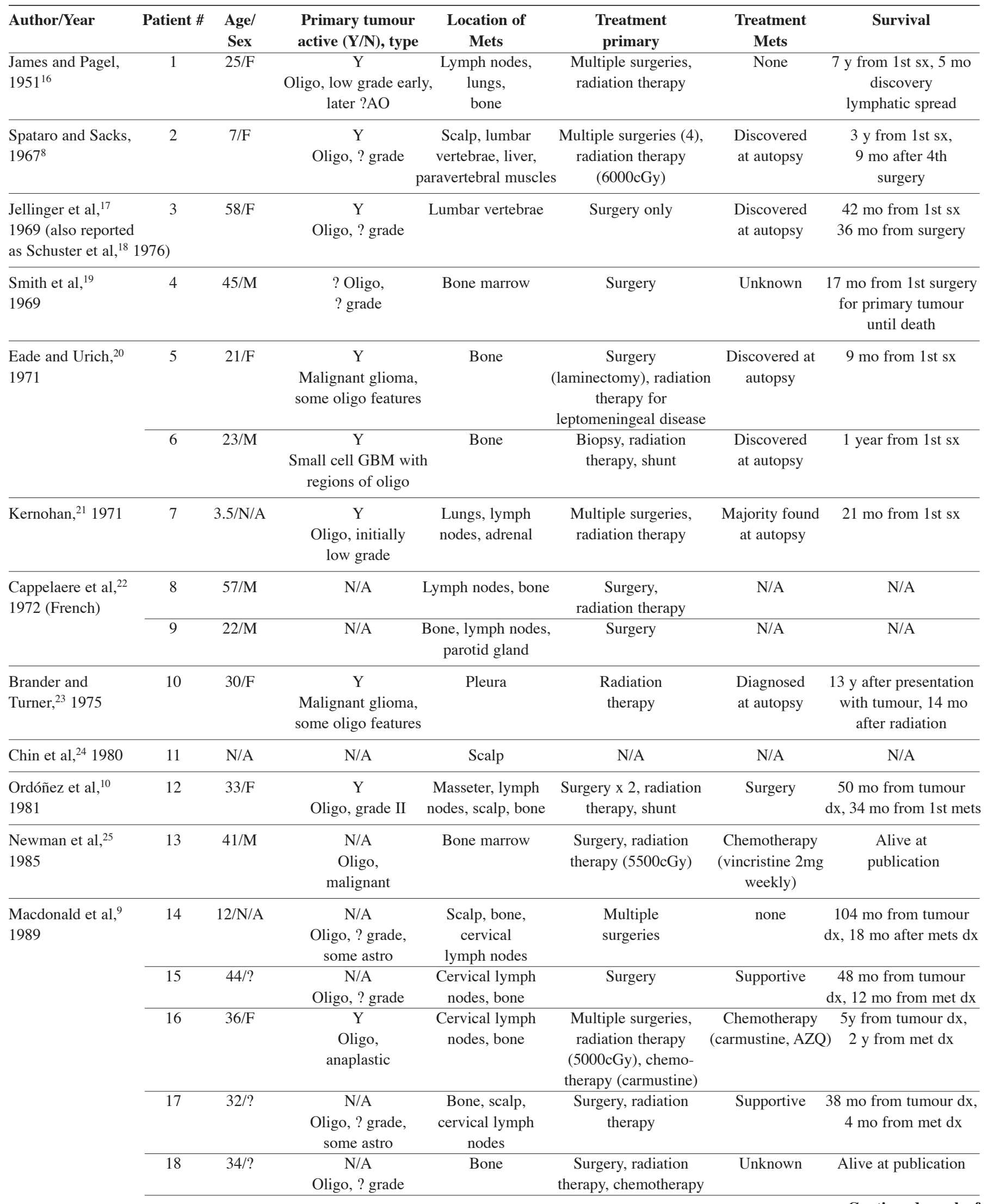

Continued overleaf 
Table 2: Clinical Features of Patients with Extracranial Metastases of Oligodendroglioma* ... continued

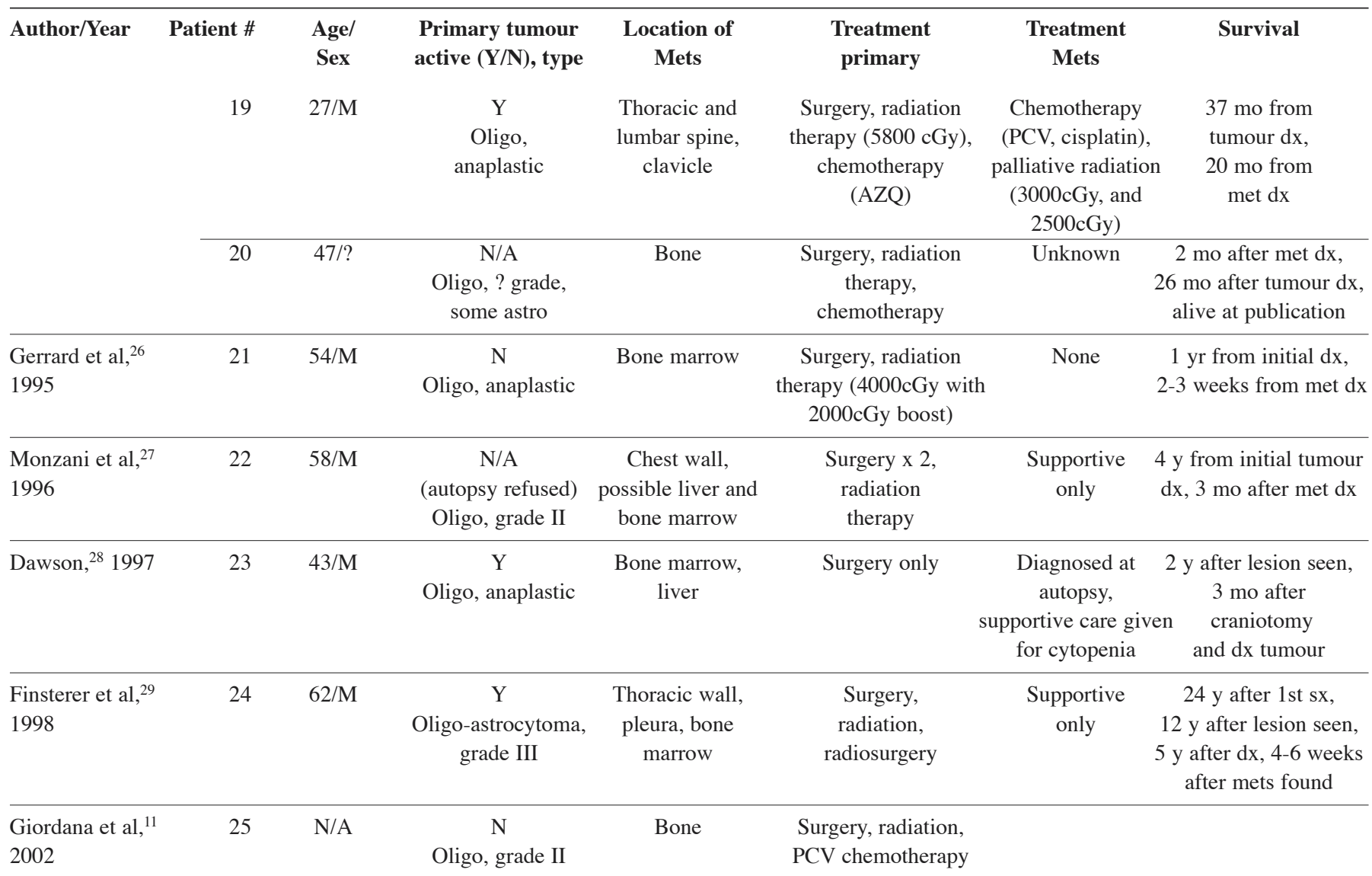

*English language literature (except patients 8\&9)

$\mathrm{M}=$ Male; F=Female; $\mathrm{Y}=\mathrm{Yes} ; \mathrm{N}=\mathrm{No}$; Oligo=oligodendroglioma; Astro=astrocytic; $\mathrm{cGy}=$ centiGray; mets=metastases; $\mathrm{AZQ}=\mathrm{diaziquinone}$;

$\mathrm{PCV}=$ Procarbazine, lomustine and vincristine; $\mathrm{mo}(\mathrm{s})=$ months; $\mathrm{y}=\mathrm{year}(\mathrm{s}) ; \mathrm{sx}=$ symptoms; $\mathrm{dx}=\mathrm{diagnosis} ; \mathrm{N} / \mathrm{A}=$ not available;

$\mathrm{GBM}=$ glioblastoma multiforme

Unfortunately, in September 2001, he began to report increasing pain on exertion, and a rise in alkaline phosphatase was noted. Bone scans reported progression of existing disease and the appearance of new foci. Pamidronate with carboplatin chemotherapy was started (a total of four cycles of pamidronate and three cycles of carboplatin were given with no lasting toxicities), however, the patient's pain continued to worsen, and his imaging continued to show progressive disease. Palliative radiation therapy became the focus of therapy in February 2002, focussing on areas of painful disease. The patient died in September 2002 of presumed pulmonary emboli due to immobility. Survival from diagnosis of metastases was 23 months, and from onset of symptoms, 29 months. An autopsy was not performed.

\section{DESIGN/MethodS}

A retrospective case review, molecular analysis and English language literature search were performed.

We used standard techniques for $\mathrm{LOH}$ analysis using microsatellite markers on the distal portion of 1p (D1S2734, D1S199, and D1S508) on tumor DNA extracted from microdissected formalin-fixed paraffin-embedded tissue and on constitutional DNA extracted from blood leukocytes.

Polymerase chain reaction (PCR) was performed on the tissue and constitutional DNA as suggested ${ }^{1-3}$ with some minor variations. The primer pair sequences and sizes for the three markers are listed in Table 1 . The reverse primer was 5'-endlabeled with polynucleotide kinase and $\gamma^{-32} \mathrm{P}$ ATP. Polymerase chain reaction was performed in $10 \mu \mathrm{l}$ volumes containing 10$20 \mathrm{ng}$ of blood or tumor DNA, 50-60 ng of each primer, and approximately $5 \mathrm{ng}$ of end-labeled primer, $200 \mu \mathrm{mol} / 1 \mathrm{dNTPs}$ and 0.25 U Taq polymerase (Perkin Elmer Life Sciences, CT) in $1.0 \mathrm{mmol} / 1 \mathrm{MgCl}_{2}$ PCR buffer. Forty cycles denaturation (30 seconds at $\left.94^{\circ} \mathrm{C}\right)$, annealing $\left(30\right.$ seconds at $\left.60^{\circ} \mathrm{C}\right)$, and elongation (30 seconds at $72^{\circ} \mathrm{C}$ ) were performed on a programmable thermal cycler (9600 system, Perkin Elmer), with extension of the first denaturation step to five minutes at $96^{\circ} \mathrm{C}$ and the last elongation step to five minutes at $72^{\circ} \mathrm{C}$. The PCR products were separated on standard denaturing $6 \%$ polyacrylamide sequencing gels at 45 watts for approximately two hours. Gels were dried 
and exposed to X-ray film (Kodak, Rochester, NY) overnight. Alleles were scored as previously suggested., ${ }^{2,4-6}$

\section{LITERATURE REVIEW}

Anaplastic oligodendroglioma is among the best characterized of the high-grade glial tumours. Its chemosensitivity is well-described and molecular characterization of predictors of chemosensitivity has been described, such as allelic loss of heterozygosity on chromosome $1 \mathrm{p} .^{7}$

The earliest descriptions of bony metastases of anaplastic oligodendroglioma, such as that of Spataro and Sacks, ${ }^{8}$ described these cases in great pathological detail. Since that time, a total of 25 cases have been reported in the English language literature (Table 2). In general, these early patients presented after multiple craniotomies but did not survive long after the development of their systemic disease. The sites of remote metastatic disease are variable; however, bone, cervical lymph nodes, and scalp are among the more common sites detected. ${ }^{9}$ Responses to chemotherapy are rarely described: one patient responded to treatment with PCV-3 chemotherapy for active intracranial disease accompanied by bony metastases; both sites of disease later recurred and did not respond to cisplatin. Another patient, who developed bone marrow involvement causing leukoerythroblastic anemia six months after completion of cranial irradiation for glioma, was treated with eight doses of vincristine $(2 \mathrm{mg})$ weekly and blood indices returned to normal. ${ }^{10}$

In contrast, the present case documents the response of bony metastases from anaplastic oligodendroglioma to chemotherapy. We speculate that the systemic metastases from our patients' original oligodendroglioma with known LOH 1p- retained their inherent chemosensitive properties. In all prior series describing systemic metastases from glioma recurrent intracranial disease was detected. This patient is unusual, as his intracranial disease remained quiescent, with metastatic disease occurring in isolation in association with a clinically dramatic and prolonged response to chemotherapy. A recent abstract ${ }^{11}$ corroborates the theorem that extended survival may contribute to the development of extracranial metastases.

The treatments used in our case were temozolomide and celecoxib. Temozolomide is an oral alkylating agent related to dacarbazine, with activity against many tumours in vitro. Phase I and II trials have shown it to have moderate efficacy in astrocytic tumours. Temozolomide also has a role in the therapy of anaplastic oligodendroglioma. Van den Bent et $\mathrm{al}^{12}$ and Chinot et $\mathrm{al}^{13}$ have studied temozolomide in patients with recurrent anaplastic oligodendrogliomas, and demonstrated substantial response in chemotherapy-naïve patients (2/3 complete response), and good responsiveness (partial and complete) in those who had received even multiple agents, including other alkylating agents (26-44\%). We used celecoxib (Celebrex ${ }^{\circledR}$ ) primarily for its anti-inflammatory effect as an adjunct to manage his significant bony pain. He attained pain relief rapidly with this within one month of initiation of therapy. The putative antiangiogenic properties of celecoxib were a secondary rationale for its selection. Though the full extent of COX-2 expression in malignant gliomas has yet to be determined, evidence suggests that more aggressive tumours express more COX-2 than COX-1. ${ }^{14}$ Celecoxib, as a COX-2 inhibitor, may inhibit progression of colorectal carcinogenesis, ${ }^{15}$ and is being actively investigated in conjunction with other chemotherapeutic agents for a potentiating effect against other cancers; the influence of celecoxib upon response obviously cannot be interpreted in this single case report.

\section{ACKNOWLEDGEMENTS}

The authors thank Dr P. Cooper of the Division of Neuroradiology, Sunnybrook and Women's College Hospital for his assistance in the selection of radiographic images and the figure explanations.

Drs. Morrison and Perry are supported by the Crolla Family Brain Tumour Research Unit and the Sunnybrook Foundation.

This paper was presented in part at the Canadian Neuro-Oncology Meeting, 10th Biennial Meeting, May 3rd-5th 2002, Montreal, Canada.

\section{REFERENCES}

1. Kraus JA, Koopmann J, Kaskel P, et al. Shared allelic losses on chromosomes $1 p$ an $19 q$ suggest a common origin of oligodendroglioma and oligoastrocytoma. J Neuropath Exp Neurol 1995; 54(1): 91-99.

2. Louis DN, von Deiming A, Seizinger BR. A (CA)n Dinucleotide repeat assay for evaluating loss of allelic heterozygosity in small and archival human brain tumor specimens. Am J Path 1992; 141(4):777-782.

3. Weber JL, May PE. Abundant class of human DNA polymophisms which can be typed using the polymerase chain reaction. Am J Hum Genet 1989; 44(3):388-396.

4. Weber JL, May PE. Dinucleotide repeat polymorphism at the D10S89 locus. Nucl Acid Res 1990; 18(16): 4637.

5. Litt M, Luty JA. A hypervariable microsatellite revealed by in vitro amplification of a dinucleotide repeat within the cardiac muscle actin gene. Am J Hum Genet 1989; 44(3):397-401.

6. Burmelster M, Cox DR, Myers RM. Dinucleotide repeat polymorphism located at D21S120. Nucl Acid Res 1990; 18(16): 4969.

7. Cairncross JG, Ueke K, Zlatescu MC, et al. Specific genetic predictors of chemotherapeutic response and survival in patients with anaplastic oligodendrogliomas. J Natl Cancer Inst 1998; 90(19): 1473-1479.

8. Spataro J, Sacks O. Oligodendroglioma with remote metastases. J Neurosurg 1968; 28(4): 373-379.

9. Macdonald DR, O'Brien RA, Gilbert JJ, Cairncross JG. Metastatic anaplastic oligodendroglioma. Neurology 1989; 39: 1593-1596.

10. Ordóñez NG, Ayala AA, Leavens ME. Extracranial metastases of oligodendroglioma: report of a case and review of the literature. Neurosurgery 1981; 8(3):391-395 (comments 395-396).

11. Giordana MT, Gasverde S, Balteri I, et al. Bone metastasis of oligodendrogliomas: clinical and molecular genetic study. NeuroOncology 2002; 4:S38e (Abstract).

12. Van den Bent MJ, Keime-Guibert F, Brandes AA, et al. Temozolomide chemotherapy in recurrent oligodendroglioma. Neurology 2001; 57(2):340-342.

13. Chinot OL, Honore S, Dufour H, et al. Safety and efficacy of temozolomide in patients with recurrent anaplastic oligodendrogliomas after standard radiotherapy and chemotherapy. J Clin Oncol 2001; 19(9): 2449-2455.

14. Deininger MH, Weller M, Streffer J, Mittelbronn M, Meyermann R. Patterns of cyclooxygenase-1 and -2 expression in human gliomas in vivo. Acta Neuropathol (Berl) 1999; 98(3):240-244.

15. Phillips RK, Wallace MH, Lynch PM, et al, FAP Study Group. A randomised, double blind, placebo controlled study of celecoxib a selective cyclooxygenase- 2 inhibitor on duodenal polyposis in familial adenomatous polyposis. Gut 2002; 50(6):857-860.

16. James TGI, Pagel W. Oligodendroglioma with extracranial metastases. Br J Surg 1951; 39:56-65.

17. Jellinger K, Minauf M, Salzer-Kuntschik M. Oligodendroglioma with extraneural metastases. J Neurol Neurosurg Psychiatr 1969; $32: 249-253$. 
18. Schuster H, Jellinger K, Gund A, Regele H. Extracranial metastases of anaplastic cerebral gliomas. Acta Neurochirugica 1976; 35:247-259.

19. Smith DR, Hardman JM, Earle KM. Metastasizing neuroectodermal tumors of the central nervous system. J Neurosurg 1969; 31:5058.

20. Eade OE, Urich H. Metastasizing gliomas in young subjects. J Pathol 1971; 103:245-256.

21. Kernohan JW. Oligodendrogliomas. In: Minckler J. (Ed) Pathology of the Nervous System. New York, McGraw-Hill Co, vol. 2, 1971:1993-2007.

22. Cappelaere P, Clay A, Adenis L, Demaille A, Laine E. Les métastases des tumeurs cérébrales primitives endehors du névraxe: a propos de trois observations. Bull Cancer (Paris) 1972; 59:235-254.

23. Brander WL, Turner DR. Extracranial metastases from a glioma in the absence of surgical intervention. J Neurol Neurosurg Psychiatry 1975; 38:1133-1135.
24. Chin HW, Hazel JJ, Kim TH, Webster JH. Oligodendrogliomas: I. A clinical study of cerebral oligodendrogliomas. Cancer 1980; 45:1458-1466.

25. Newman HFV, Howard GCW, Reid PM. Metastatic oligodendroglioma presenting as a leukoerythroblastic anemia. Eur J Surg Onc 1985; 11: 287-288.

26. Gerrard GE, Bond MG, Jack AS. Bone marrow infiltration by a parietal lobe grade III oligodendroglioma. Clin Oncol 1995; 7:321-322.

27. Monzani V, Rovellini A, Masini B, Cappricci E, Miserocchi G. Metastatic oligodendroglioma. Case report. J Neurol Sci 1996;40(3-4):239-241.

28. Dawson TP. Case report. Pancytopenia from a disseminated anaplastic oligodendroglioma. Neuropathol App Neurobiol 1997; 23:516-520.

29. Finsterer J, Breiteneder S, Mueller MR, et al. Pleural and bone marrow metastasis from supratentorial oligoastrocytoma grade III. Oncology 1998; 55:345-348. 